\title{
PROJECT CARE: THE IMPORTANCE OF MULTIDISCIPLINARY WORK IN THE CARE OF PATIENTS IN AN INFUSION CENTER IN SÃO JOSÉ DOS CAMPOS/SP
}

Luiz Claudio Ramos de Albuquerque1, ${ }^{1, \star}$, Kátia Batista de Medeiros², Luciano Allan Agra dos Santos ${ }^{1}$, Vanessa Karina Bispo Macedo ${ }^{1}$, Samille Maria Bandeira Freitas Pacheco ${ }^{1}$

1.Acredite - Gestão, Estratégia e Qualidade, Maceió (AL), Brazil; 2.Vale Infusões, São José dos Campos (SP), Brazil.

*Corresponding author: claudio@acreditequalidade.com

\section{BACKGROUND}

Multidisciplinary care of patients in the treatment of chronic diseases has a unique importance in therapy and in the maintenance of quality of life. Especially when it comes to patients who have a clinical need for assisted infusion treatment. The care model based on prevention, recovery and personalized rehabilitation for each individual helps in a favorable response to the established therapeutic planning. In addition to bringing benefits to a proven source of care (health plans, unified health care or the patient's own costs) as it is expected that the patient followed up as needed will present a lower number of complications and, consequently, hospital or highly complex operations.

\section{CASE REPORT}

The CUIDE-SE project was created by the multidisciplinary team of an assisted therapy center (ATC) with units in São José dos Campos and Itaquera, São Paulo state, Brazil; having as one of its pillars the humanized care involving medical care within various specialties (rheumatologists, gastroenterologists, dermatologists, etc.) and a multidisciplinary team (nurses, psychologists, nutritionists and physiotherapists). Its scope is patients who use medication or infusion for the treatment of chronic diseases, of all age groups from the Brazilian unified health system, health insurance or privately. The specialized body is not part of the internal and external project, activated according to the needs of each patient. On average, 10 instances of service in the specialties are offered, at no additional cost.

\section{CONCLUSION}

The treatment of patients with chronic pain is a challenge for ATCs, the advancement of immunobiological treatments is essential for the management of these patients. However, there are other aspects related to their quality of life, which are of paramount importance for the success of the established therapeutic project. It was observed that multidisciplinary work contributes through the establishment of a space for speech and self-knowledge through psychology, change of eating habits through nutrition, and knowledge of the body itself and overcoming physiotherapy. The CUIDE-SE project showed that systemic care has a significant impact on the quality of life of the patient and on adherence to the established medical treatment.

\section{KEYWORDS}

Multidisciplinary, Infusion center, Assisted therapy service, Cuide-se, Project care. 